\title{
Non-testosterone management of male hypogonadism: an examination of the existing literature
}

\author{
Sarah C. Krzastek, Ryan P. Smith \\ Department of Urology, University of Virginia, Charlottesville, VA, USA \\ Contributions: (I) Conception and design: All authors; (II) Administrative support: RP Smith; (III) Provision of study materials or patients: None; (IV) \\ Collection and assembly of data: None; (V) Data analysis and interpretation: None; (VI) Manuscript writing: All authors; (VII) Final approval of \\ manuscript: All authors. \\ Correspondence to: Sarah C. Krzastek. Department of Urology, University of Virginia, 500 Ray C. Hunt Drive, Charlottesville, VA 22903, USA. \\ Email: Sarah.Krzastek@vcuhealth.org.
}

\begin{abstract}
Testosterone deficiency is defined as a total testosterone level $<300 \mathrm{ng} / \mathrm{dL}$ confirmed on two early morning lab draws. Testosterone therapy has historically been offered to men with symptomatic testosterone deficiency in the form of injections, gels, or pellets. However, these treatments are invasive or have undesirable effects including the risk of drug transference. Additionally, testosterone therapy has been associated with increases in hematocrit and controversy remains regarding the risk of cardiovascular and thromboembolic events while on testosterone therapy. As such, much interest has recently been focused on alternative treatment options for testosterone deficiency in the form of orally-administered medications with more favorable side effect profiles. Lifestyle modifications and varicocelectomy have been shown to raise endogenous testosterone production. Similarly, SERMs and aromatase inhibitors (AIs) have been shown to raise testosterone levels safely and effectively. Human chorionic gonadotropin (hCG) remains the only FDA-approved non-testosterone treatment option for testosterone deficiency in men. However, this medication is expensive and requires patient-administered injections. Over the counter herbal supplements and designer steroids remain available though they are poorly studied and are associated with the potential for abuse as well as increased hepatic and cardiovascular risks. This review aims to discuss the existing treatment alternatives to traditional testosterone therapy, including efficacy, safety, and side effects of these options. The authors suggest that the SERM clomiphene citrate (CC) holds the greatest promise as a nontestosterone treatment option for testosterone deficiency.
\end{abstract}

Keywords: Aromatase inhibitors (AIs); gonadotropins; hypogonadism; selective estrogen receptor modulators (SERMs); testosterone

Submitted May 15, 2019. Accepted for publication Nov 05, 2019.

doi: $10.21037 /$ tau.2019.11.16

View this article at: http://dx.doi.org/10.21037/tau.2019.11.16

\section{Introduction}

Hypogonadism, or testosterone deficiency in the male, is defined by the American Urological Association (AUA) as a total testosterone level less than $300 \mathrm{ng} / \mathrm{dL}$ on early morning blood draw on two separate occasions (1). Testosterone deficiency is highly prevalent, with rates increasing with age from $4 \%$ in men aged $40-49$ years to nearly $50 \%$ in men over 80 years of age, with some studies suggesting a $17 \%$ increase in testosterone deficiency for every decade of life (2-4).

The AUA Panel on the Evaluation and Management of Testosterone Deficiency suggests that to be eligible for testosterone therapy patients must have low testosterone levels combined with symptoms or signs associated with low testosterone (1). Historically, testosterone deficiency has been treated with various formulations of exogenous testosterone. Exogenous testosterone, however, bypasses 


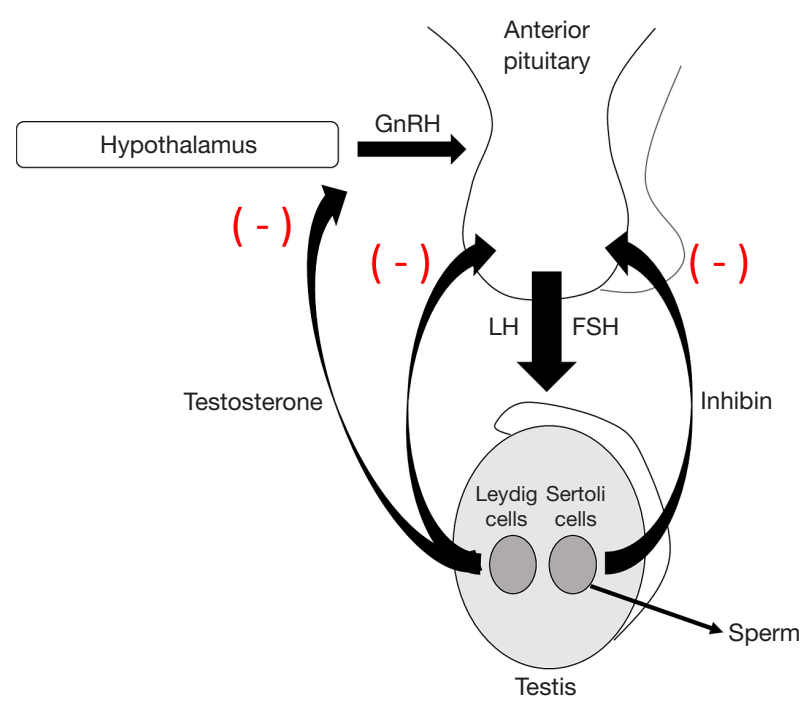

Figure 1 Hypothalamus-pituitary-gonadal axis. The hypothalamus releases $\mathrm{GnRH}$ in a pulsatile fashion, which stimulates the anterior pituitary to release $\mathrm{LH}$ and FSH to stimulate testosterone production and spermatogenesis in the testis. Testosterone negatively feeds back on the pituitary to suppress LH release. GnRH, gonadotropin-releasing hormone; LH, luteinizing hormone; FSH, follicle stimulating hormone.

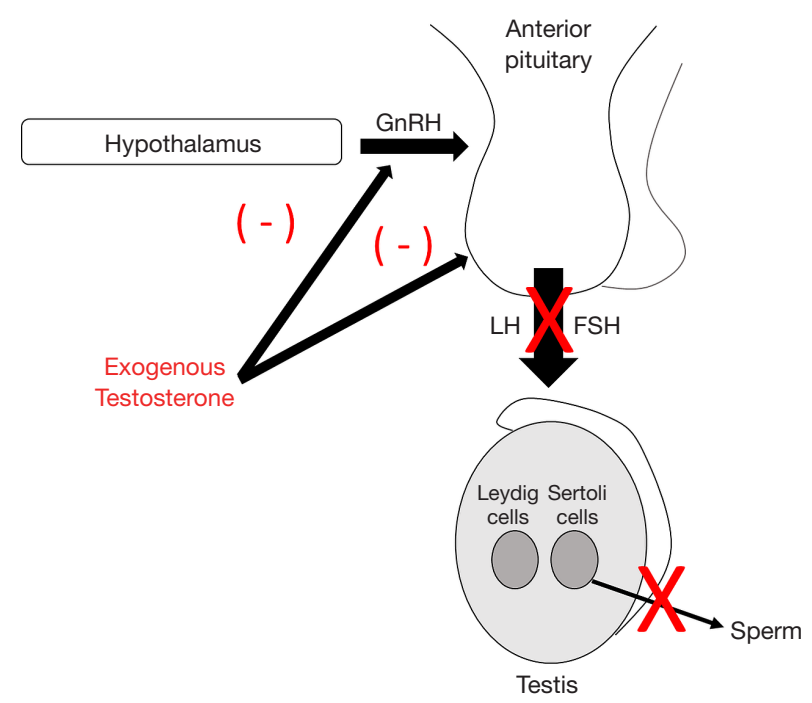

Figure 2 The effect of exogenous testosterone on the HPG axis. Exogenous testosterone suppresses the release of GnRH and LH, resulting in testicular atrophy and suppression of spermatogenesis. HPG, hypothalamic-pituitary-gonadal; GnRH, gonadotropinreleasing hormone; $\mathrm{LH}$, luteinizing hormone; $\mathrm{FSH}$, follicle stimulating hormone. the body's natural ability to produce testosterone, thus leading to the downregulation of luteinizing hormone $(\mathrm{LH})$ and follicle stimulating hormone ( $\mathrm{FSH})$ with suppression of the hypothalamic-pituitary-gonadal (HPG) axis and spermatogenesis (5). (Figures 1,2) Additionally, many formulations of exogenous testosterone require invasive administration via injections and can result in large swings in serum testosterone levels with associated recurrence of symptoms. Alternative formulations of exogenous testosterone, such as gels or creams, have the risk of transference to others. Though testosterone therapy improves bone mineral density, lean body mass, erectile function, and anemia, there is inconclusive evidence on the benefits of testosterone therapy on cognitive function, energy levels, blood glucose or lipid levels, and controversy remains around whether testosterone therapy affects the risk of cardiovascular events (6-13). Testosterone therapy may also lead to polycythemia, and while some studies have not linked testosterone therapy to increases in venothrombolic events (VTE), other studies suggest that there is an increased risk of VTE in the first six months of treatment, and warnings regarding cardiovascular and embolic events remain in the drug packaging information $(14,15)$.

Given the side effects and controversies of exogenous testosterone therapy, much work has been done to identify effective alternatives to treat symptomatic testosterone deficiency. This review aims to discuss in detail the options for management of testosterone deficiency in men, outside of exogenous testosterone.

\section{Non-medication management options}

\section{Lifestyle modifications}

Studies have shown that both low testosterone and obesity increase the risk of major adverse cardiac events $(16,17)$. Recent preliminary data have shown that low endogenous testosterone levels are associated with lower high-density lipoprotein (HDL) cholesterol and higher low-density lipoprotein cholesterol, triglyceride, and total cholesterol levels (18). As such, the AUA recommends counseling men with testosterone deficiency to increase physical activity and maintain their weight within the recommended range to reduce the signs and symptoms of testosterone deficiency and increase serum testosterone levels (1). ArmamentoVillareal and colleagues reported that dietary interventions, with and without exercise, resulted in significant increases 
in total testosterone levels (19). Similarly, Moran et al. reported on 68 men participating in a weight-loss diet. Men lost a mean of $10.3-10.8 \pm 1.2 \mathrm{~kg}$ over the 52 -week study period and experienced significant increases in total and free testosterone $(\mathrm{P}<0.001$ and $\mathrm{P}=0.002$, respectively). Additionally, men with moderate to severe baseline erectile dysfunction had significant increases in the International Index of Erectile Function (IIEF) erectile function domain following weight loss (20). More recently, Rigon and colleagues evaluated 29 men with a mean baseline weight of $155.26 \pm 25.88 \mathrm{~kg}$ preoperatively and 6 months postoperatively following bariatric surgery. BMI improved to a mean of $37.82 \pm 5.94 \mathrm{~kg}$ following surgery, with improvements in total testosterone levels from $229.53 \pm 96.45 \mathrm{ng} / \mathrm{dL}$ to $388.38 \pm 160.91 \mathrm{ng} / \mathrm{dL}(\mathrm{P}<0.001)(21)$.

Aside from maintaining a healthy weight, sleep quality has been associated with symptoms of testosterone deficiency. Pastuszak et al. noted a linear relationship between self-reported sleep quality and symptoms of testosterone deficiency as quantified by the Androgen Deficiency in the Aging Male (ADAM) questionnaire (22). Though studies show conflicting results regarding the relationship between sleep hours or quality and testosterone levels, most studies suggest a correlation between sleep quality and symptoms of testosterone deficiency (23). In general, lifestyle modifications to include healthy sleep with diet and exercise to maintain a normal weight and activity level are safe and effectively raise endogenous testosterone levels. These recommendations should be included as part of the counseling and management options for men with testosterone deficiency.

\section{Varicocelectomy}

Surgical repair of a varicocele, if present, may also be a treatment option for testosterone deficiency, and has been shown to increase testosterone levels in men with testosterone deficiency. Sathya et al. assessed 100 men with primary or secondary infertility, with average testosterone of $177 \mathrm{ng} / \mathrm{dL}$ and clinical varicocele, who underwent microscopic varicocelectomy. Following varicocelectomy, testosterone rose significantly to a mean of $301 \mathrm{ng} / \mathrm{dL}(\mathrm{P}<0.001)(24)$. The authors hypothesized that varicocelectomy might improve endogenous testosterone production via reducing testicular hyperthermia, improving the activity of 17,20-desmolase and 17-alpha-hydroxylase enzymes (Figure 3), and improving Leydig cell response to LH stimulation (24). It has been shown that the incidence of varicocele increases with age and the negative impact of a varicocele on testicular function is progressive, but studies indicate that varicocelectomy improves testosterone levels in hypogonadal men in their 40 and 50s as much as younger men (25-28). Offering varicocelectomy to men with a clinical varicocele and testosterone deficiency may naturally improve endogenous testosterone production and avoid long-term testosterone therapy and associated monitoring and side effects, both in men with subfertility, and in men in whom fertility preservation is not of concern. However, whether those improvements in serum testosterone levels translate into clinically meaningful improvements in symptoms of hypogonadism remains controversial (29). At present, varicocelectomy is not recommended solely for the indication of hypogonadism.

\section{Oral supplements}

The discussion of symptoms associated with "low T" in popular culture has led to an increase in demand for products aimed at improving energy levels and sex drive, even among men without a formal diagnosis of testosterone deficiency (30). Many compounds are being marketed as oral dietary supplements or adjuncts to "boost" testosterone. However, studies suggest that oral formulations of testosterone fail to improve symptoms of testosterone deficiency and do not raise serum testosterone levels above placebo due to a lack of bioavailability with an oral formulation (31). Despite this, there is continued interest in oral over-the-counter supplements to treat symptoms of testosterone deficiency (32).

\section{Androgenic-anabolic and designer steroids}

Anabolic steroids are compounds synthesized to be structurally like testosterone, but with a longer duration of action and increased bioavailability. These compounds are marketed as performance-enhancing agents. While short-term use may lead to increased muscle mass, longterm use has been associated with increased risks of hepatic dysfunction, carcinoma, and cardiovascular disease, as well as prolonged testicular suppression and subfertility (33-35). "Designer steroids" are androgenic-anabolic steroids chemically modified with the intent to avoid legal restrictions on controlled substances. Many of these compounds are novel, with no published research on their safety or efficacy and have varying anabolic effects, but may still be associated with dependence, hypertension, 


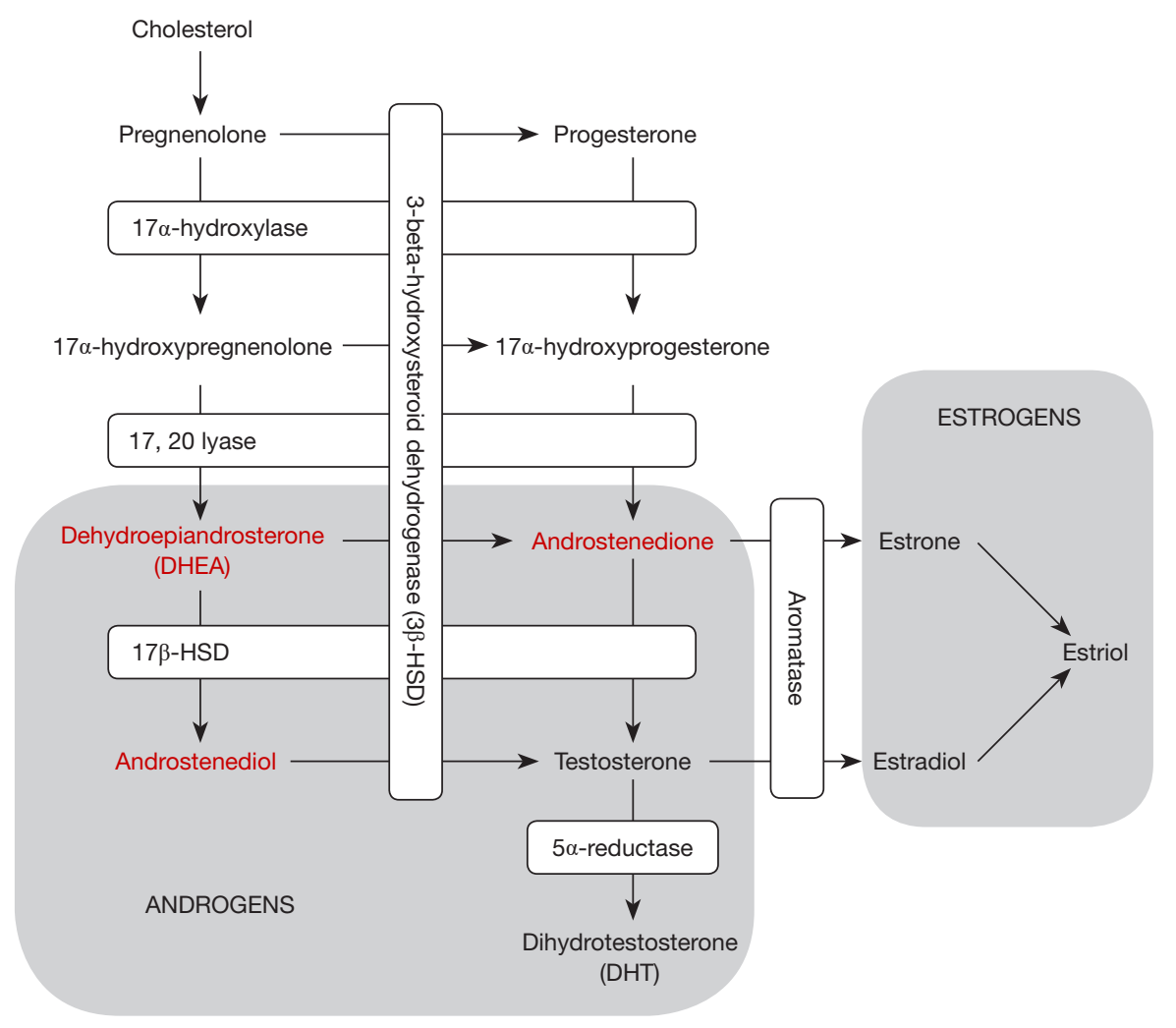

Figure 3 Steroid regulation pathway. Adapted from Kovac JR, Pan M, Arent S, et al. Dietary Adjuncts for Improving Testosterone Levels in Hypogonadal Males. Am J Mens Health 2016;10:NP109-17. copyright (C) 2016 by @ SAGE Publications; Reprinted by Permission of SAGE Publications, Inc.

polycythemia, liver toxicity, and subfertility (35).

Kovac and colleagues published a review in 2016 of three commercially available oral testosterone dietary adjuncts marketed to "boost" testosterone, including androstenedione, androstenediol, and dehydroepiandroterone (DHEA) (30). In 2004, the US Department of Health and Human Services and the Food and Drug Administration passed the Anabolic Steroid Control Act which listed anabolic steroids including androstenedione and androstenediol as controlled substances, making it illegal to obtain these without a physician prescription.

Androstenedione and androstenediol are precursors to testosterone and are converted into testosterone by 17-betahydroxysteroid dehydrogenase and 3-beta-hydroxysteroid dehydrogenase, respectively (Figure 3). Studies have shown that oral androstenedione and androstenediol supplementation increases serum levels of androstenedione and estradiol (E2) $(36,37)$. Serum testosterone levels increase but return to the pretreatment baseline after 12 weeks of use (37). The authors hypothesize that this return to pretreatment baseline testosterone level is due to increased aromatization of peripheral androstenedione and testosterone with conversion to estrone and E2, respectively (37). Neither supplementation with androstenedione or androstenediol improved muscular strength or body composition in patients taking these supplements, and both resulted in worsened HDL cholesterol profiles and increased cardiovascular risk (37).

DHEA is a precursor to androstenedione and androstenediol (Figure 3) and is a weak partial androgen receptor agonist (30). While this compound is regulated in Europe, it is still available over the counter in the United States. A 2013 meta-analysis of 25 randomized controlled trials studying DHEA use in over 1,300 men found that DHEA supplementation was associated with small improvements in body fat composition, but no improvements were noted in total serum testosterone, glucose or lipid profiles, bone mineral density, or mental or physical quality of life outcomes (38). Additionally, studies have shown that DHEA supplementation does not improve 
erectile function (39).

Numerous other compounds with steroid-like structures are not regulated and have been identified in dietary supplements marketed to "enhance performance," with one report finding that synthetic oral anabolic-androgenic steroids have been detected in up to $20 \%$ of performanceenhancing drugs sold legally over the counter $(35,40,41)$. This is concerning, as many patients may not be aware of the potential health risks associated with exogenous steroid use, and even if they are, they may not be aware that these compounds are present in their oral supplements. Currently, oral "testosterone boosting" supplements are not recommended for the treatment of testosterone deficiency.

\section{Herbal supplements}

Many herbal supplements are also marketed towards "boosting" testosterone levels, including onion (Allium cepa L.), ginger (Zingiber officinale), maca root (Lepidium), fenugreek (Trigonella foenum-graecum), Tribulus (Tribulus Terrestris), Tinospora cardifolia, and black seeds (Nigella sativa) (42-44). Onion is thought to work by increasing the production of $\mathrm{LH}$ and reducing testicular reactive oxygen species (ROS) (42). Ginger has been hypothesized to improve testosterone production by reducing ROS in the testis (43). Tribulus Terrestris and Tinospora cardifolia have questionable effects on testosterone levels $(30,44)$. Additionally, most studies have been performed in animals, and data regarding changes in testosterone levels in humans is lacking.

Fenugreek seeds have been touted to have a wide range of health benefits and anti-inflammatory properties and have been used to treat women's health conditions, diabetes, and hypercholesterolism (45). It has been suggested that this compound also improves testosterone levels and symptoms associated with testosterone deficiency $(46,47)$. This compound is thought to have androgenic effects via its soluble steroidal saponin content and incomplete 5-alpha reductase and aromatase inhibitor (AIs) activity (47). A study by Maheshwari et al. treated 50 men aged 35-65 diagnosed with symptomatic hypogonadism with $500 \mathrm{mg}$ of daily fenugreek seed extract for 12 weeks. Subjects experienced a significant increase in free testosterone ( $8 \mathrm{vs}$. $12 \mathrm{pg} / \mathrm{mL}, \mathrm{P}=0.004)$, but no significant increase was noted in total testosterone ( $405 v s .436 \mathrm{ng} / \mathrm{dL}, \mathrm{P}=0.16$ ), following 12 weeks of treatment (45). Improvements in sperm count and motility were also noted after 4, 8, and 12 weeks of treatment, with improvements in sperm morphology, noted at 8 and 12 weeks (45). No changes were noted in DHEA levels, fasting blood sugars, liver enzymes, cholesterol levels, or total leukocyte counts (45). This treatment appears to be well tolerated and effective, but long-term data regarding safety and efficacy are lacking, and further studies need to be performed before the establishment of fenugreek as a viable option for treating testosterone deficiency.

Another compound that has gained interest in the treatment of male hypogonadism is zinc. Zinc deficiency has been linked to decreased spermatogenesis and testosterone production (48). Liu et al. randomized 67 men with isolated hypogonadotropic hypogonadism to receive FSH or FSH plus $40 \mathrm{mg}$ zinc for 18 months (48). They found no differences in serum testosterone levels between groups throughout the study period. Similarly, studies suggest that the use of zinc alone is ineffective in increasing testosterone levels (49). Overall, while certain herbal supplements appear to be well tolerated, with preliminary data suggesting increases in testosterone levels, prospective randomized controlled trials in humans must be conducted to demonstrate safety and efficacy before these compounds can be supported for use in the management of testosterone deficiency.

\section{Accepted non-testosterone management options}

As exogenous testosterone suppresses spermatogenesis, several compounds are used off-label to treat testosterone deficiency in men desiring to preserve fertility. The AUA states that selective estrogen receptor modulators (SERMs), AIs, and human chorionic gonadotropin (hCG) may be used alone or in combination to treat testosterone deficiency in this population (1). These compounds act at various locations within the HPG axis to upregulate the body's endogenous testosterone production and serum levels (Figure 4).

\section{SERMs}

SERMs block the negative feedback of E2 on the hypothalamus, resulting in increased $\mathrm{LH}$ production and increased downstream testosterone production (Figure 4). These medications are orally administered which improves patient compliance.

The SERM most studied in the treatment of testosterone deficiency is clomiphene citrate (CC). CC has long been used as a treatment to restore testosterone levels and promote or preserve spermatogenesis in men with 


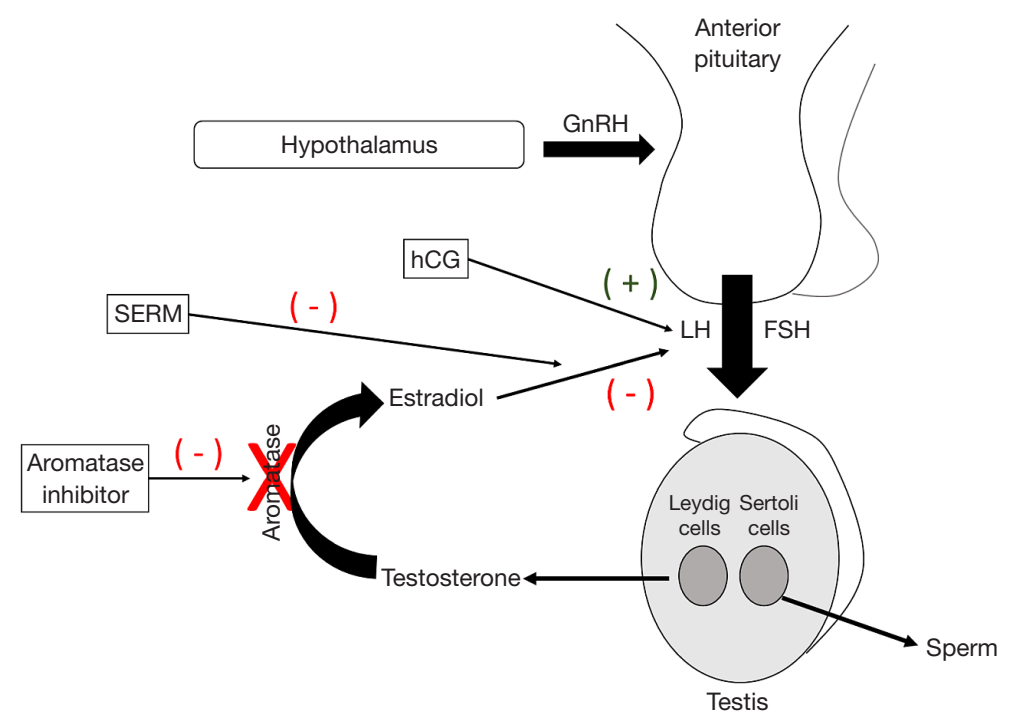

Figure 4 Sites of action of SERMs, aromatase inhibitors, and hCG in the HPG axis. SERMs, selective estrogen receptor modulators; hCG, human chorionic gonadotropin; HPG, hypothalamic-pituitary-gonadal; GnRH, gonadotropin-releasing hormone; LH, luteinizing hormone; FSH, follicle stimulating hormone.

testosterone deficiency desiring to preserve fertility, and multiple studies have shown that CC effectively raises testosterone to eugonadal levels (50-56). This medication is an oral compound administered at doses ranging from $25 \mathrm{mg}$ every other day, to $50 \mathrm{mg}$ daily, based on testosterone response. Moskovic et al. reported on 29 men with a baseline total testosterone level of $228 \pm 48 \mathrm{ng} / \mathrm{dL}$ treated for $>3$ years with CC. They demonstrated improvements in testosterone to a mean of $582 \pm 227 \mathrm{ng} / \mathrm{dL}(\mathrm{P}<0.001)$, as well as significant improvements in $\mathrm{ADAM}$ questionnaire response $(\mathrm{P}=0.01)$ and mean $\mathrm{BMI}(\mathrm{P}<0.05)(50)$. Similarly, Taylor and Levine demonstrated that compared to testosterone gel therapy, CC treatment resulted in equivalent, significant improvements in testosterone levels at a fraction of the cost, as well as significant improvements in ADAM questionnaire scores. No patients discontinued CC treatment due to side effects, and no adverse events on CC were reported. Additionally, patients on CC treatment did not experience changes in hemoglobin, PSA, or cholesterol levels while on treatment (51). Ramasamy et al. have also demonstrated that quantitative ADAM scores were similar among patients treated with CC as compared to those treated with testosterone gels or injections, with improvements in testosterone levels while on CC treatment to physiologic levels (54).

Still, CC has not historically been offered as a first line treatment for testosterone deficiency in men not desiring fertility preservation given its off-label use and lack of longterm data regarding safety and efficacy. In the setting of these limitations, ongoing studies are being conducted to establish long-term treatment outcomes. CC is welltolerated. Rare side effects include headaches, visual changes, and gynecomastia (50). Additionally, CC use has shown to have significantly less risk of increased hematocrit as compared to testosterone therapy (57). Preliminary data on men treated for testosterone deficiency on CC for as long as 7 years show that over $80 \%$ of men achieve testosterone levels $>450 \mathrm{ng} / \mathrm{dL}$, with $78 \%$ of men reporting subjective improvement in hypogonadal symptoms, and only $9 \%$ reporting side effects from CC treatment with no significant adverse events (58). This data together suggests that CC may be a safe and effective treatment option for the long-term management of testosterone deficiency, and consideration should be made to offering this therapy to men as a first-line treatment option for testosterone deficiency, regardless of the patient's desire for fertility preservation.

Enclomiphene citrate (EC) is a trans-isomer of CC and is not currently FDA approved in the United States. Like CC, $\mathrm{EC}$ has been shown to raise testosterone and gonadotropin levels, while preserving spermatogenesis (59). Additionally, EC treatment may deliver the androgenic effects of CC without the side effects associated with CC, though further studies need to be conducted to determine if EC has clinically superior selectivity (60). 
Like CC, tamoxifen has been shown to increase testosterone and gonadotropin levels, and preserve spermatogenesis, and this SERM is an acknowledged alternative treatment option for testosterone deficiency in men $(1,61)$. Tamoxifen has been used to stimulate gonadotropin production, and to treat gynecomastia in the setting of anabolic steroid-induced hypogonadism or hCG treatment (62). However, the adverse effects associated with tamoxifen appear to be greater than those associated with CC use, including gastrointestinal distress, venous thromboembolic events, and other cardiovascular outcomes (63). As such, tamoxifen is less commonly used for the treatment of testosterone deficiency.

\section{AIs}

Like SERMs, AIs, including letrozole and anastrozole, are also designed to block E2 inhibition of the HPG axis by preventing aromatization of testosterone to E2 in the tissues, thus upregulating endogenous testosterone production (Figure 4). These compounds have been shown to raise testosterone levels in hypogonadal men and are also orally administered (64-66). Historically, AIs have been administered concurrently with testosterone therapy to normalize the testosterone-to-estradiol (T:E2) ratio, correct iatrogenic elevations in E2, and treat associated subfertility (67).

Dias et al. treated 14 hypogonadal men with $1 \mathrm{mg}$ of anastrozole daily for 12 months. Men treated with AI had significant increases in total testosterone levels over the study course. Of note, lumbar spine bone mineral density was lower in men treated with AI compared to those on testosterone therapy (66). The same group subsequently evaluated the effect of a 12 -month treatment of AI on glucose levels and cardiovascular risk markers. After 12 months, fasting glucose, insulin, and lipid levels were not different between men treated with $\mathrm{AI}$ and men treated with testosterone therapy (68). However, questions remain regarding the clinical significance of $\mathrm{AI}$-associated changes in testosterone levels and T:E2 ratios, as some studies have failed to show improvements in psychological or physiological parameters or symptoms of hypogonadism with these associated changes $(69,70)$.

AIs are well-tolerated, but side effects may include nausea, the elevation of liver enzymes, headaches, and hot flashes (71). As long-term AI use has been associated with decreases in bone mineral density due to suppression of E2, the AUA recommends against the use of AI for prolonged periods $(1,72)$. Additionally, if used to correct the T:E2 ratio, a dose of $1 \mathrm{mg}$ two to three times per week is suggested (67).

\section{Gonadotropins}

Gonadotropin replacement therapy is an option for treating hypogonadotropic hypogonadism and includes gonadotropin-releasing hormone $(\mathrm{GnRH})$ and the $\mathrm{LH}$ analog hCG. Both compounds can be administered subcutaneously. GnRH administration requires the use of a continuous infusion pump to titrate GnRH levels to mimic the pulsatile release of GnRH from the hypothalamus, and this treatment modality is still considered experimental (67).

Of the non-testosterone compounds used to treat testosterone deficiency in men, only hCG is FDA approved (1). hCG is an LH analog and stimulates testosterone production by binding LH receptors. hCG has also been used with concurrent exogenous testosterone to maintain intratesticular testosterone levels and preserve spermatogenesis (73). Liu et al. randomized 40 hypogonadal men over the age of 60 to receive either 5,000 IU of hCG or placebo twice per week for 3 months. Patients treated with hCG had significant increases in total and free testosterone (74). More recently, Habous et al. treated 94 men with $5000 \mathrm{IU}$ of hCG twice per week for 3 months. They similarly found significant increases in testosterone levels with hCG treatment (75). While hCG acts directly on the testis and is well-tolerated, this medication is expensive, and with the requirement for multiple injections per week, many patients elect alternative treatments (34).

\section{Future directions}

Several novel targets for increasing endogenous testosterone production are being investigated. Nerve growth factor has been shown to increase testosterone and LH levels in mice and is thought to promote the pulsatile synthesis and release of GnRH (76). Luo et al. recently demonstrated that intranasal delivery of nerve growth factor twice per week for 12 weeks in senescent mice resulted in increased levels of LH, FSH and testosterone, increased intratesticular testosterone, and increases in measures of sexual behavior in mice, including mounting and ejaculation times (76). If these results are reproducible in humans, intranasal nerve growth factors would be a promising minimally-invasive treatment option to promote the restoration of endogenous testosterone production. Similarly, oxytocin has also been shown to stimulate $\mathrm{GnRH}$ release, and it has been 
hypothesized that intranasal oxytocin may be a potential therapeutic option for testosterone deficiency in the future $(77,78)$. Additionally, research into herbal compounds for the treatment of testosterone deficiency is ongoing $(79,80)$.

Lastly, recent interest has increased around selective androgen receptor modulators (SARMs). SARMs are a newer class of agents with tissue-specific effects like those seen with SERMs and can be tailored to have specific effects within certain tissues while reducing undesired non-specific or androgenic side effects. These compounds are currently being investigated as treatment options for hypogonadism, as they are orally administered and are relatively welltolerated with few adverse events, though some concern exists as to whether these lead to hepatotoxicity and decreased levels of HLD cholesterol (81).

\section{Conclusions}

Given the prevalence of testosterone deficiency in men, and the desire to avoid testosterone therapy and its associated effects on testicular volume, spermatogenesis and the HPG axis with possible adverse side effects, much work has been done to identify safe and efficacious alternative treatment options. Lifestyle modifications are safe and have been shown to increase endogenous testosterone production and should be offered to all men desiring treatment of testosterone deficiency. Varicocelectomy, with further study, may become a valid treatment option in the presence of a clinical varicocele. While numerous compounds exist marketed towards "boosting testosterone," data on the safety and efficacy of these are poor, and these are not currently recommended as treatments for testosterone deficiency. Gonadotropins, including hCG (the only nontestosterone agent FDA approved for the treatment of male hypogonadism), are effective, but costly and require administration via injection. AIs may also raise testosterone levels but may be associated with decreases in bone mineral density if used long-term. SERMs, including clomiphene citrate, appear to be highly effective at producing physiologic testosterone levels and appear to be welltolerated and safe when used long-term. Consideration may be given to offering clomiphene citrate to men with symptomatic testosterone, regardless of the patient's desire to preserve fertility. While studies exist suggesting that many of these treatment options are well tolerated and efficacious, further prospective studies must be conducted to support their use as first line treatment options in the management of testosterone deficiency.

\section{Acknowledgments}

Funding: None.

\section{Footnote}

Provenance and Peer Review: This article was commissioned by the Guest Editors (Larry I. Lipshultz, Alexander W. Pastuszak) for the focused issue "Contemporary Issues and Controversies in Men's Health" published in Translational Andrology and Urology. The article was sent for external peer review organized by the Guest Editors and the editorial office.

Conflicts of Interest: The focused issue "Contemporary Issues and Controversies in Men's Health" was commissioned by the editorial office without any funding or sponsorship. The authors have no conflicts of interest to declare.

Ethical Statement: The authors are accountable for all aspects of the work in ensuring that questions related to the accuracy or integrity of any part of the work are appropriately investigated and resolved.

Open Access Statement: This is an Open Access article distributed in accordance with the Creative Commons Attribution-NonCommercial-NoDerivs 4.0 International License (CC BY-NC-ND 4.0), which permits the noncommercial replication and distribution of the article with the strict proviso that no changes or edits are made and the original work is properly cited (including links to both the formal publication through the relevant DOI and the license). See: https://creativecommons.org/licenses/by-nc-nd/4.0/.

\section{References}

1. Mulhall JP, Trost LW, Brannigan RE, et al. Evaluation and Management of Testosterone Deficiency: AUA Guideline. J Urol 2018;200:423-32.

2. Araujo AB, O'Donnell AB, Brambilla DJ, et al. Prevalence and incidence of androgen deficiency in middle-aged and older men: estimates from the Massachusetts Male Aging Study. J Clin Endocrinol Metab 2004;89:5920-6.

3. Harman SM, Metter EJ, Tobin JD, et al. Longitudinal effects of aging on serum total and free testosterone levels in healthy men. Baltimore Longitudinal Study of Aging. J Clin Endocrinol Metab 2001;86:724-31.

4. Mulligan T, Frick MF, Zuraw QC, et al. Prevalence of 
hypogonadism in males aged at least 45 years: the HIM study. Int J Clin Pract 2006;60:762-9.

5. MacIndoe JH, Perry PJ, Yates WR, et al. Testosterone suppression of the HPT axis. J Investig Med 1997;45:441-7.

6. Amory JK, Watts NB, Easley KA, et al. Exogenous testosterone or testosterone with finasteride increases bone mineral density in older men with low serum testosterone. J Clin Endocrinol Metab 2004;89:503-10.

7. Corona G, Monami M, Rastrelli G, et al. Type 2 diabetes mellitus and testosterone: a meta-analysis study. Int J Androl 2011;34:528-40.

8. Snyder PJ, Ellenberg SS, Farrar JT. Testosterone Treatment in Older Men. N Engl J Med 2016;375:90.

9. Resnick SM, Matsumoto AM, Stephens-Shields AJ, et al. Testosterone Treatment and Cognitive Function in Older Men With Low Testosterone and Age-Associated Memory Impairment. JAMA 2017;317:717-27.

10. Brock G, Heiselman D, Maggi M, et al. Effect of Testosterone Solution 2\% on Testosterone Concentration, Sex Drive and Energy in Hypogonadal Men: Results of a Placebo Controlled Study. J Urol 2016;195:699-705.

11. Grossmann M, Hoermann R, Wittert G, et al. Effects of testosterone treatment on glucose metabolism and symptoms in men with type 2 diabetes and the metabolic syndrome: a systematic review and meta-analysis of randomized controlled clinical trials. Clin Endocrinol (Oxf) 2015;83:344-51.

12. Corona G, Giagulli VA, Maseroli E, et al. THERAPY OF ENDOCRINE DISEASE: Testosterone supplementation and body composition: results from a meta-analysis study. Eur J Endocrinol 2016;174:R99-116.

13. Corona G, Rastrelli G, Di Pasquale G, et al. Testosterone and Cardiovascular Risk: Meta-Analysis of Interventional Studies. J Sex Med 2018;15:820-38.

14. Baillargeon J, Urban RJ, Morgentaler A, et al. Risk of Venous Thromboembolism in Men Receiving Testosterone Therapy. Mayo Clin Proc 2015;90:1038-45.

15. Martinez C, Suissa S, Rietbrock S, et al. Testosterone treatment and risk of venous thromboembolism: population based case-control study. BMJ 2016;355:i5968.

16. Araujo AB, Dixon JM, Suarez EA, et al. Clinical review: Endogenous testosterone and mortality in men: a systematic review and meta-analysis. J Clin Endocrinol Metab 2011;96:3007-19.

17. Bastien M, Poirier P, Lemieux I, et al. Overview of epidemiology and contribution of obesity to cardiovascular disease. Prog Cardiovasc Dis 2014;56:369-81.

18. Harris KT, Herati AS, Andriole GL, et al. MP85-20: Relationship Between Endogenous Testosterone and
Lipid Parmeters: Insight From REDUCE Study Group Database. J Urol 2018. doi: 10.1016/j.juro.2018.02.2880.

19. Armamento-Villareal R, Aguirre LE, Qualls C, et al. Effect of Lifestyle Intervention on the Hormonal Profile of Frail, Obese Older Men. J Nutr Health Aging 2016;20:334-40.

20. Moran LJ, Brinkworth GD, Martin S, et al. Long-Term Effects of a Randomised Controlled Trial Comparing High Protein or High Carbohydrate Weight Loss Diets on Testosterone, SHBG, Erectile and Urinary Function in Overweight and Obese Men. PLoS One 2016;11:e0161297.

21. Rigon FA, Ronsoni MF, Hohl A, et al. Effects of Bariatric Surgery in Male Obesity-Associated Hypogonadism. Obes Surg 2019;29:2115-25.

22. Pastuszak AW, Moon YM, Scovell J, et al. Poor Sleep Quality Predicts Hypogonadal Symptoms and Sexual Dysfunction in Male Nonstandard Shift Workers. Urology 2017;102:121-5.

23. Deng N, Kohn TP, Lipshultz LI, et al. The Relationship Between Shift Work and Men's Health. Sex Med Rev 2018;6:446-56.

24. Sathya Srini V, Belur Veerachari S. Does varicocelectomy improve gonadal function in men with hypogonadism and infertility? Analysis of a prospective study. Int J Endocrinol 2011;2011:916380.

25. Levinger $\mathrm{U}$, Gornish $M$, Gat $Y$, et al. Is varicocele prevalence increasing with age? Andrologia 2007;39:77-80.

26. Bernie HL, Goldstein M. Varicocele Repair Versus Testosterone Therapy for Older Hypogonadal Men with Clinical Varicocele and Low Testosterone. Eur Urol Focus 2018;4:314-6.

27. Dabaja AA, Goldstein M. When is a varicocele repair indicated: the dilemma of hypogonadism and erectile dysfunction? Asian J Androl 2016;18:213-6.

28. Hsiao W, Rosoff JS, Pale JR, et al. Older age is associated with similar improvements in semen parameters and testosterone after subinguinal microsurgical varicocelectomy. J Urol 2011;185:620-5.

29. Khourdaji I, Lee H, Smith RP. Frontiers in hormone therapy for male infertility. Transl Androl Urol 2018;7:S353-66.

30. Kovac JR, Pan M, Arent S, et al. Dietary Adjuncts for Improving Testosterone Levels in Hypogonadal Males. Am J Mens Health 2016;10:NP109-17.

31. Morales A, Black A, Emerson L, et al. Androgens and sexual function: a placebo-controlled, randomized, doubleblind study of testosterone vs. dehydroepiandrosterone in men with sexual dysfunction and androgen deficiency. Aging Male 2009;12:104-12.

32. Balasubramanian A, Thirumavalavan N, Srivatsav A, 
et al. Testosterone Imposters: An Analysis of Popular Online Testosterone Boosting Supplements. J Sex Med 2019;16:203-12.

33. Christou MA, Christou PA, Markozannes G, et al. Effects of Anabolic Androgenic Steroids on the Reproductive System of Athletes and Recreational Users: A Systematic Review and Meta-Analysis. Sports Med 2017;47:1869-83.

34. Tatem AJ, Beilan J, Kovac JR, et al. Management of Anabolic Steroid-Induced Infertility: Novel Strategies for Fertility Maintenance and Recovery. World J Mens Health 2019. [Epub ahead of print].

35. Rahnema CD, Crosnoe LE, Kim ED. Designer steroids - over-the-counter supplements and their androgenic component: review of an increasing problem. Andrology 2015;3:150-5.

36. Leder BZ, Longcope C, Catlin DH, et al. Oral androstenedione administration and serum testosterone concentrations in young men. JAMA 2000;283:779-82.

37. Broeder CE, Quindry J, Brittingham K, et al. The Andro Project: physiological and hormonal influences of androstenedione supplementation in men 35 to 65 years old participating in a high-intensity resistance training program. Arch Intern Med 2000;160:3093-104.

38. Corona G, Rastrelli G, Giagulli VA, et al. Dehydroepiandrosterone supplementation in elderly men: a meta-analysis study of placebo-controlled trials. J Clin Endocrinol Metab 2013;98:3615-26.

39. El-Sakka AI. Dehydroepiandrosterone and Erectile Function: A Review. World J Mens Health 2018;36:183-91.

40. Lorenz LM, Toomey VM, Lanzarotta AC, et al. Identification of the designer steroid Androsta-3,5-diene7,17-dione in a dietary supplement. Drug Test Anal 2019;11:1109-15.

41. Cawley AT, Blakey K, Waller CC, et al. Detection and metabolic investigations of a novel designer steroid: 3 -chloro-17 $\alpha$-methyl-5 $\alpha$-androstan-17 $\beta$-ol. Drug Test Anal 2016;8:621-32.

42. Banihani SA. Testosterone in Males as Enhanced by Onion (Allium Cepa L.). Biomolecules 2019. doi: 10.3390/ biom9020075.

43. Banihani SA. Ginger and Testosterone. Biomolecules 2018. doi:10.3390/biom8040119.

44. Santos HO, Howell S, Teixeira FJ. Beyond tribulus (Tribulus terrestris L.): The effects of phytotherapics on testosterone, sperm and prostate parameters. J Ethnopharmacol 2019;235:392-405.

45. Maheshwari A, Verma N, Swaroop A, et al. Efficacy of FurosapTM, a novel Trigonella foenum-graecum seed extract, in Enhancing Testosterone Level and Improving Sperm Profile in Male Volunteers. Int J Med Sci 2017;14:58-66.

46. Steels E, Rao A, Vitetta L. Physiological aspects of male libido enhanced by standardized Trigonella foenumgraecum extract and mineral formulation. Phytother Res 2011;25:1294-300.

47. Rao A, Steels E, Inder WJ, et al. Testofen, a specialised Trigonella foenum-graecum seed extract reduces agerelated symptoms of androgen decrease, increases testosterone levels and improves sexual function in healthy aging males in a double-blind randomised clinical study. Aging Male 2016;19:134-42.

48. Liu YL, Zhang MN, Tong GY, et al. The effectiveness of zinc supplementation in men with isolated hypogonadotropic hypogonadism. Asian J Androl 2017;19:280-5.

49. Santos HO, Teixeira FJ. Use of medicinal doses of zinc as a safe and efficient coadjutant in the treatment of male hypogonadism. Aging Male 2019. [Epub ahead of print].

50. Moskovic DJ, Katz DJ, Akhavan A, et al. Clomiphene citrate is safe and effective for long-term management of hypogonadism. BJU Int 2012;110:1524-8.

51. Taylor F, Levine L. Clomiphene citrate and testosterone gel replacement therapy for male hypogonadism: efficacy and treatment cost. J Sex Med 2010;7:269-76.

52. Mazzola CR, Katz DJ, Loghmanieh N, et al. Predicting biochemical response to clomiphene citrate in men with hypogonadism. J Sex Med 2014;11:2302-7.

53. Katz DJ, Nabulsi O, Tal R, et al. Outcomes of clomiphene citrate treatment in young hypogonadal men. BJU Int 2012;110:573-8.

54. Ramasamy R, Scovell JM, Kovac JR, et al. Testosterone supplementation versus clomiphene citrate for hypogonadism: an age matched comparison of satisfaction and efficacy. J Urol 2014;192:875-9.

55. Chandrapal JC, Nielson S, Patel DP, et al. Characterising the safety of clomiphene citrate in male patients through prostate-specific antigen, haematocrit, and testosterone levels. BJU Int 2016;118:994-1000.

56. Guay AT, Jacobson J, Perez JB, et al. Clomiphene increases free testosterone levels in men with both secondary hypogonadism and erectile dysfunction: who does and does not benefit? Int J Impot Res 2003;15:156-65.

57. Wheeler KM, Smith RP, Kumar RA, et al. A Comparison of Secondary Polycythemia in Hypogonadal Men Treated with Clomiphene Citrate versus Testosterone Replacement: A Multi-Institutional Study. J Urol 2017;197:1127-31.

58. Krzastek SC, Sharma D, Abdullah N, et al. Long- 
Term Safety and Efficacy of Clomiphene Citrate for the Treatment of Hypogonadism. J Urol 2019;202:1029-35.

59. Kim ED, McCullough A, Kaminetsky J. Oral enclomiphene citrate raises testosterone and preserves sperm counts in obese hypogonadal men, unlike topical testosterone: restoration instead of replacement. BJU Int 2016;117:677-85.

60. Earl JA, Kim ED. Enclomiphene citrate: A treatment that maintains fertility in men with secondary hypogonadism. Expert Rev Endocrinol Metab 2019;14:157-65.

61. Dony JM, Smals AG, Rolland R, et al. Effect of lower versus higher doses of tamoxifen on pituitary-gonadal function and sperm indices in oligozoospermic men. Andrologia 1985;17:369-78.

62. Rahnema CD, Lipshultz LI, Crosnoe LE, et al. Anabolic steroid-induced hypogonadism: diagnosis and treatment. Fertil Steril 2014;101:1271-9.

63. Wibowo E, Pollock PA, Hollis N, et al. Tamoxifen in men: a review of adverse events. Andrology 2016;4:776-88.

64. 'T'Sjoen G, Giagulli VA, Delva H, et al. Comparative assessment in young and elderly men of the gonadotropin response to aromatase inhibition. J Clin Endocrinol Metab 2005;90:5717-22.

65. Leder BZ, Rohrer JL, Rubin SD, et al. Effects of aromatase inhibition in elderly men with low or borderline-low serum testosterone levels. J Clin Endocrinol Metab 2004;89:1174-80.

66. Dias JP, Melvin D, Simonsick EM, et al. Effects of aromatase inhibition vs. testosterone in older men with low testosterone: randomized-controlled trial. Andrology 2016;4:33-40.

67. Carrasquillo R, Chu K, Ramasamy R. Novel Therapy for Male Hypogonadism. Curr Urol Rep 2018;19:63.

68. Dias JP, Shardell MD, Carlson OD, et al. Testosterone vs. aromatase inhibitor in older men with low testosterone: effects on cardiometabolic parameters. Andrology 2017;5:31-40.

69. Loves S, de Jong J, van Sorge A, et al. Somatic and psychological effects of low-dose aromatase inhibition in men with obesity-related hypogonadotropic hypotestosteronemia. Eur J Endocrinol 2013;169:705-14.

70. Helo S, Ellen J, Mechlin C, et al. A Randomized Prospective Double-Blind Comparison Trial of Clomiphene Citrate and Anastrozole in Raising Testosterone in Hypogonadal Infertile Men. J Sex Med 2015;12:1761-9.

71. Gregoriou O, Bakas P, Grigoriadis C, et al. Changes in hormonal profile and seminal parameters with use of aromatase inhibitors in management of infertile men with low testosterone to estradiol ratios. Fertil Steril
2012;98:48-51.

72. Burnett-Bowie SA, McKay EA, Lee H, et al. Effects of aromatase inhibition on bone mineral density and bone turnover in older men with low testosterone levels. J Clin Endocrinol Metab 2009;94:4785-92.

73. Coviello AD, Matsumoto AM, Bremner WJ, et al. Low-dose human chorionic gonadotropin maintains intratesticular testosterone in normal men with testosterone-induced gonadotropin suppression. J Clin Endocrinol Metab 2005;90:2595-602.

74. Liu PY, Wishart SM, Handelsman DJ. A doubleblind, placebo-controlled, randomized clinical trial of recombinant human chorionic gonadotropin on muscle strength and physical function and activity in older men with partial age-related androgen deficiency. J Clin Endocrinol Metab 2002;87:3125-35.

75. Habous M, Giona S, Tealab A, et al. Clomiphene citrate and human chorionic gonadotropin are both effective in restoring testosterone in hypogonadism: a short-course randomized study. BJU Int 2018;122:889-97.

76. Luo J, Yang Y, Zhang T, et al. Nasal delivery of nerve growth factor rescue hypogonadism by up-regulating $\mathrm{GnRH}$ and testosterone in aging male mice. EBioMedicine 2018;35:295-306.

77. Selvage D, Johnston CA. Central stimulatory influence of oxytocin on preovulatory gonadotropin-releasing hormone requires more than the median eminence. Neuroendocrinology 2001;74:129-34.

78. Salehi MS, Pandamooz S, Khazali H. Oxytocin intranasal administration as a new hope for hypogonadotropic hypogonadism patients. Med Hypotheses 2017;109:88-9.

79. Jung MA, Oh $\mathrm{KN}$, Choi EJ, et al. In vitro and in vivo androgen regulation of Dendropanax morbiferus leaf extract on late-onset hypogonadism. Cell Mol Biol (Noisyle-grand) 2018;64:20-7.

80. Lee KW, Bae SR, Jeong HC, et al. A randomized, controlled study of treatment with ojayeonjonghwan for patients with late onset hypogonadism. Aging Male 2018. doi: 10.1080/13685538.2018.1480599.

81. Solomon ZJ, Mirabal JR, Mazur DJ, et al. Selective Androgen Receptor Modulators: Current Knowledge and Clinical Applications. Sex Med Rev 2019;7:84-94.

Cite this article as: Krzastek SC, Smith RP. Non-testosterone management of male hypogonadism: an examination of the existing literature. Transl Androl Urol 2020;9(Suppl 2):S160S170. doi: 10.21037/tau.2019.11.16 